\title{
Coordinative Abilities Importance in Selection Process Optimi- zation of Young Children for the Handball Game: A Question- naire Overview
}

\author{
Ileana Petrariu ${ }^{1, *}$
}

1 Affiliation 1; ileana.petrariu@usm.ro
* Correspondence: ileana.petrariu@usm.ro

\begin{abstract}
According to the reviewed literature, the selection system in the handball game is quite complex and requires new approaches from specialists, based on the current requirements of this game. It was found that a main selection criterion in the game of handball is the coordination abilities because the handball game is mainly based on coordination. In this paper is related the importance of coordinative abilities development in the handball game for young children (10-12 years old) selection process meet in Romania. The results are obtained from a sociological questionnaire, where 109 specialists in the handball game are interrogated, 38 of them being handball coaches, and 71 being teachers of physical education and sports with abilities in handball game. The answers delivered depend on each specialist experience, the knowledge possessed and the difficulties encountered over the years. As a general overview, in the opinion of the surveyed specialists, the selection process in the handball game for Romania does not live up to their expectations, and the development level of coordination abilities meet in 10-12 years children is medium to weak. A total of $51.9 \%$ from the respondents stressed the importance of developing coordination abilities to optimize the selection process of children for handball game, opening a new approach in the modern training methods for performance achievement.
\end{abstract}

Keywords: coordination abilities, training, handball, physical activity

\section{Introduction}

The need for a thorough and forward-looking training of athletes is a major concern of researchers in terms of modern sports training nowadays. Training of tomorrow's athletes' team is considered an important priority and it's the main concern of the researchers, who try to make various contributions and improvements in sports training components considering the age of the athletes [1, 2, 3].

Many scientific reports have shown the optimal age to start training in different sports. In handball, Nabatnikova M.V. [4] and Manno R. [5] argue that the optimal period for the initial training is the age of 10 to 13 years, being followed by 12 to 17 years old for early specialization and continued to 16 to 18 years old for performance improvement. The author from [6] supplement the mentioned above, including non-traditional training methods. They offer the possibility to individualize the training program of athletes, provide important information about the qualitative and quantitative parameters of motor and psychomotor actions of subjects, support the coach in activity planning during training and are designed to learn the external characteristics of movement, without to invoke the internal structure of the motor skills.

With the increase in sports performance, the content of sports training has become increasingly complex resulting in changing of methodology. This fact has led to significant changes in the sports training content systematization, the development of this process following some strict rules and principles. According to [7], one of these rules aims to establish the purpose and the result of the physical exercise performed, a key element in 
sports training. Sports evolution is determined by the performances level. Thus, in sports, the body is trained to control its movements in unusual conditions, such as imbalances, jumps or coordination, conditions that require a complex skill management system. Also, the same authors claim that perceptual-motor learning process involves a change in the athlete's behavior, depending on the live and unique conditions that occur in the training process or in the sports competitions. Thus, the individual reacts with an answer that can be perfected in terms of coordination, accuracy, rhythm etc. This reaction, which become a skill, is adjusted (through several interventions) until a perfect concordance is obtained between the anticipated image and the effective action. Thus, specific motor skills reach the final level of fluency, precision, coordination and tempo through stereotypical repetitions.

At a sports medicine congress held in Rome in [8], it was stated that to obtain sports performance, the process of selecting individuals would have an importance of $70 \%$, thus $30 \%$ from the total would go to the sports training. One can easily observe the major importance that researchers grant it to the selection process, this being considered the key to performance in contemporary sport area. As a general definition supported by the researchers $[9,10,11]$ the selection process is a systematic and organized activity, a process of sorting and identification, carried out by coaches based on rigorously established criteria, to detect early children with special skills for practicing and specializing in a particular sport branch to obtain sports performance.

In handball game, the organization of the selection process aims to cover as many candidates for selection as possible and tries to effectively use the mean of selection by involving the most appropriate diagnostic methods. However, for the selection to be carried out correctly and to lead to sports performance, some well-established rules must be strictly observed, some of them being listed below [12].

- establishing the optimal age of selection, the age at which the skills and motor qualities of the individual are obvious and can have a maximum efficiency in guaranteeing the achievement of performances in the chosen sport branch.

- the selection criteria established to be adequate to the particularities of the sport branch.

- the rejection system is recommended in the first stage of selection and training, although sometimes are rejected individuals who can achieve superior results in the future activity.

- the specific selection tests within the sport branch will be applied in ascending order, according to the individual age, gender, level of development and training particularities.

- the selected individuals must be in phase to the regional sport particularities, the sporting tradition, the training conditions, and sports facility, and with the social, economic, and professional environment conditions which may lead to improvement of motor skills and abilities.

The enhancement of the skills and qualities of future athletes can be achieved through an extensive instructive-educational process, called sports training [13]. The success of this extensive training process is determined by goals establishment, choosing the right content, methods and techniques of learning and assessment, which lead to capitalizing on the physical, mental, and biological potential of the individual. Some define and describe sports training in terms of its general components: physical, technical-tactical, intellectual, mental, and moral training, being a complex and planned process, and from a biomedical point of view, it aims to evolve upwards according to the objective of morpho functional adaptation. Of all the training components, the physical training is the most important. This implies the increase of the physiological potential of the individual, but also the development of the basic motor qualities: speed, skill, strength, endurance, mobility, and suppleness, but also of the specific ones.

At the same time, modern sports training is oriented towards fulfilling a set of clear training objectives:

- increase of motor capacity. 
- harmonious physical development and specific to the chosen sport branch.

- development of basic motor skills and formation of the foundation for the development of combined or specific motor skills.

- the correct learning of the basic technical and tactical procedures from the practiced sport.

- brief introduction of specialization and game tasks.

- participation in competitions with an optimal level of training.

In preparing children aged 10-12 for the handball game, many researchers believe that modern sports training has as its main components the physical, technical, tactical, theoretical, and psychological training [14, 15, 16, 17]. The sports training objectives for children and juniors are mentioned below.

- developing the motor capacity that can be achieved through the borrowed means from other sports (athletics, gymnastics, adapted sports games and dynamic games). These are the basis for the technical-tactical skills specific to the handball game development.

- harmonious physical development, objective achievable through posture exercises, breathing exercises, but also through bilateral analytical work, execution of specific exercises with the clumsy body part.

- development of motor qualities specific to the stage of physical development, speed, and skill. Of course, the development of motor qualities, strength and endurance is also tried, but they are approached on a secondary level.

- the initiation in the specific handball game technique, where the correct skills and specific technical procedures are imposed.

- having an appropriate behavior in the training or competitions activity (fair play, perseverance, punctuality, discipline, respect, collaboration), but also outside the sports sphere, respecting the basic principles for a balanced life (rest, nutrition, hygiene, etc.).

The optimization of the training process involves material, organizational and medical factors, referring to the increase of the registered performances, but also to the complexity of the training of the performance athletes.

The issue of optimizing the selection system in sports games, especially in the handball game is particularly important. In the reviewed literature, the authors consider that the selection determines approximately $70-75 \%$ of a great athlete destiny $[18,19,20]$. Talent must be found in a timely manner and included in a training system conducted in full harmony with the educational process.

Analyzing the ways of accomplishing the process of selection and sports training in our country, but also in other countries, such as France, Poland, or Spain, it was possible to draw some similarities, and differences. Among the similarities are the concept of the game, the basis of selection, the basic material conditions, but also the age of selection for initiation in the handball game. At the same time, the training period from the initiation in the handball game to the achievement of great performances is comparable. Regarding the differences between the four countries listed, we can mention the large number of handball players. Thus, in 2019 in France there were approximately 55,000 legitimate athletes, compared to only 6,000 legitimate athletes in Romania. Also, the financial support is clearly superior in the other countries compared to the one in Romania, but also the professional level of the specialists in the field who are included in an extremely efficient system of continuous training [20, 21, 22, 23].

Nowadays, there is a decrease in the sports selection age compared to the existing model for children. This trend has developed from the need to quickly obtain sports performances, the continuous increase of the technical and tactical mastery levels, facts that determine the intensification of all aspects of training young athletes. The lesson and training of future athletes creates important problems due to the reduction of the period of performance of athletes in the "great performance", which requires the re-recruitment and completion of groups of athletes participating in major competitions [24].

According to some authors [20,25], the average age of onset in the handball game for men is 11.6 years, and the average age at which they obtained the first performance is 22.6. 
Also, the Olympic champions in the handball game between 1896-1992 had an average age of 28.4 years.

A study performed in [26] highlights the age at which handball players reach a maximum level of performance. The study targeted the players involved in the final tournament of the Champions League from 2012. The conclusions surprise that the period of maximum performance recorded by professional handball players is around 25 to 35 years old. To confirm the data from the study, the athletes were monitored at all major competitions during 2003-2012.

The essence of the selection process is to establish a diagnosis, a prognosis regarding the future evolution of sports performance. In this process, the basic tool is the tests. Numerous issues related to this approach were discussed at meetings of the European Federation for Sport and Body Activities, the main purpose being to standardize tests in the field of sport. It was concluded that age-appropriate psychomotor tests should be used in the selection process, and it was proposed to establish test packages specific to different sport branches [27, 28].

A modern trend that allows the selection system optimization is that of the introduction of tests that assess the coordination skills level development. Handball is a game mainly based on coordination, but in the selection tests of children in our country, coordination skills are tested only through technical tests. The ability to coordinate is determined by a control process and movements regulation. They allow the control of predictable and unpredictable actions. Here, we can distinguish two categories. The first category includes the ability of general coordination, as a result of multipurpose motor acquisitions that allow the performance of motor tasks in an inventive, personal manner. The second category includes the specific coordination abilities, developed within a sports discipline that allow the choice of tactical combinations specific to the respective sports game. Generalized training of coordination skills is complex and requires the identification and prioritization of each component to be developed (combining ability, analytical ability, balance, orientation, rhythm, reaction, readjustment, or readjustment) [29, 30].

Testing in the selection process is a major importance factor. Various scientific studies attest to this. In most countries where is a performance history in the handball game, they have adopted various new selection strategies, various tests to facilitate the recruitment of young talents for the handball game [6,31,32,33]. These studies propose some test packages that evaluate the general physical development, the coordinative capacity, the motor and psychic development, but also some social aspects.

In a study conducted in Poland, researchers proposed a test package for the selection of children in the handball game, which include somatic measurements, motor tests and tests that equate the level of coordinative skills development. The latter are evaluated by tests where simple reaction time to visual stimuli, complex reaction time to visual stimuli, visual-motor coordination (a modified test involving equipment - Piórkowski), spatial orientation, ambidexterity, perception - sense of direction are measured. The study's conclusions show that assessing the level of development of coordination skills is extremely important in the process of handball game children selection [32].

Numerous studies conducted in France and Canada also propose the inclusion of coordination tests in the process of selecting children for the handball game, in addition to those that assess general motor skills and physical development. The authors propose tests such as: 9-3-6-3-9, the peripheral vision test, for the reaction speed, for throwing the ball to the target, for zig-zag running, for moving in a triangle. The conclusions of these studies also emphasize the importance of including tests for assessing coordination skills in test packages for the handball game children selection process [33, 34, 35].

Therefore, the process of optimizing the selection in the handball game is very important, conditioning the obtaining of the subsequent performances. The model pursued by species-listers from other countries, where the handball game has spectacular results, should be integrated in our country as well. Currently, the selection in Romania is carried out according to certain principles and rules that are no longer up-to date, which determines a regression from a performance point of view. 
The specialized literature is diversified in terms of selection issues, but it is largely optional, and lacks the solutions that coaches are looking for. The harmonious combination of motor, morphological, psychological, and functional criteria, taking into account the optimal age of selection, health and integrity of the body, are arguments that argue in favor of this information.

Awareness of the importance of carrying out the selection process on a well-determined scientific basis, the constant attempt to find specific innovative solutions, the application of the criteria listed in optimal conditions provides the appropriate framework for initiation into sports activity that aims to achieve performance.

The main purpose of this study was to investigate if the development of coordination skills in optimizing the selection process of 10-12-year-olds for the handball game is important and whether this aspect can define the improvements in sports performance of a handball team. The study started due to the presumption that the development of coordination skills at this age is very important, especially since around the age of 7-12 years, they can be developed up to $75 \%$ of the maximum development potential reached in adolescence. At the age of 10-12 years old, the development of coordination is intense, allowing the rapid acquisition of the technical-tactical elements of the handball game, improving the reaction capacity in different situations of collaboration or adversity, developing the anticipation spirit and space-time orientation. The emphasis on the coordination skills development at this age lies in the plasticity of the nervous system, in motor habits that are not permanently fixed, can be corrected and perfected, which makes it easier for children to quickly learn this game.

The novelty and originality of this paper involves validating the need for the selection process through the level of coordination skills development of children aged 10-12 years old using a questionnaire that is completed by 109 specialists in the field, some of them being handball coaches of junior or seniors' teams met in Romania. The applicative value of the paper consists in the fact that the obtained results can be used as methodological benchmarks by handball coaches and teachers in specialized schools and sports clubs, as well as in the professional training of students in higher education institutions of physical education and sports with handball specialization.

\section{Materials and Methods}

The research was carried out in good conditions, the teachers and specialized coaches were cooperative, and the results obtained could be considered for defining conclusions on the importance of using children selection process in the handball game. The entire research was organized in the following activities:

- studying and analyzing the specialized literature on the topic.

- selecting the questions from the sociological survey that would have a definite impact for the conclusions of the research topic.

- conducting the survey and interpreting the data.

- representation and graphical interpretation of the results obtained.

To achieve this important goal, a 13 questions questionnaire was made and distributed to the subject of our research. The questions were asked and arranged so that the specialists' opinions would be as useful as possible for the research and to be able to highlight the specific aspects of the children selection process problem for the handball game with the development of coordination skills. The methodology for the questionnaire application was strictly followed in order not to influence the result obtained.

The questionnaire was applied to 109 specialists in the field of handball, 38 of them are handball coaches, and 71 are teachers of physical education and sports with abilities in Romanian handball game. The experience in the field of the 109 teachers / coaches varies from 3 to over 30 years, some of them obtaining important results in sports competitions with involvement in the handball game (being coaches of junior or senior teams). They offered the answers to the 13 questions depending on one's own experience, the knowledge possessed, the problems of the lesson and the difficulties encountered over the years. 
Table 1. Questions from the questionnaire proposed to evaluate the importance of coordination abilities in selection process of children for handball game

\begin{tabular}{ll}
\hline No. & \multicolumn{1}{c}{ Question } \\
\hline $\mathbf{1}$ & $\begin{array}{l}\text { How do you appreciate the quality of the selection made in the sports games in } \\
\text { Romania? }\end{array}$ \\
\hline $\mathbf{2}$ & $\begin{array}{l}\text { How do you appreciate the quality of the selection made in Romania for the hand- } \\
\text { ball game? }\end{array}$ \\
\hline $\mathbf{3}$ & $\begin{array}{l}\text { What do you consider to be the most effective selection criteria that specialists } \\
\text { should give more importance to? }\end{array}$ \\
\hline $\mathbf{4}$ & $\begin{array}{l}\text { In your opinion, which of the components from sports training occupies the most } \\
\text { important place in sports training? }\end{array}$ \\
\hline $\mathbf{5}$ & $\begin{array}{l}\text { Which of the listed motor qualities play an important role in optimizing the se- } \\
\text { lection process of handball athletes? (Indicate three motor qualities) }\end{array}$ \\
\hline $\mathbf{6}$ & $\begin{array}{l}\text { Which of the components of coordination abilities occupy an important place in } \\
\text { the training process of handball players? }\end{array}$ \\
\hline $\mathbf{7}$ & $\begin{array}{l}\text { How do you assess the level of development of coordination abilities in the case } \\
\text { of children aged 10-12 years old selected for handball game? }\end{array}$ \\
\hline $\mathbf{8}$ & $\begin{array}{l}\text { How much importance is given to the development of coordination abilities of } \\
\text { children aged 10-12 in handball training? }\end{array}$ \\
\hline $\mathbf{9}$ & $\begin{array}{l}\text { What number of lessons per week (or lesson topics), from the annual training } \\
\text { planning of your handball players, do you give for the development of coordina- } \\
\text { tion abilities? }\end{array}$ \\
\hline $\mathbf{1 0}$ & $\begin{array}{l}\text { In what period of training of handball athletes is more importance given to the } \\
\text { development of coordination abilities? }\end{array}$ \\
\hline $\mathbf{1 1}$ & $\begin{array}{l}\text { In which part of the handball training lesson do you approach the development } \\
\text { of coordination abilities? }\end{array}$ \\
\hline $\mathbf{1 2}$ & $\begin{array}{l}\text { How much time do you spend to teach using coordinating abilities in a handball } \\
\text { sports training lesson? }\end{array}$ \\
\hline $\mathbf{1 3}$ & $\begin{array}{l}\text { How important is the level of coordination abilities development in optimizing } \\
\text { the selection process for the handball game? }\end{array}$ \\
\hline
\end{tabular}

\section{Results and Discussion}

Next, we will present the answers of the specialists to the 13 questions, with the comments accordingly. From the analysis of the specialists' opinions, we established the necessity of the proposed approach, the importance of the topic in the specialized literature, but also the importance of developing the coordinative capacities for the handball game.

To the question number 1 "How do you appreciate the quality of the selection made in the sports games in Romania?" most of the specialists rated the quality of the selection in our country as "satisfactory" $45.5 \%, 32.5 \%$ of those surveyed rated the quality of the selection as "good", 18.2\% answered "poor", and 3.9\% ticked the "very weak" answer (Figure 1). It can be seen that the percentage difference between the answers of the specialists who checked the "satisfactory" option, and the "good" option is relatively small, but we can conclude that most specialists are not satisfied with the quality of the selection process in our country, meaning that there is a possibility to make improvements. 


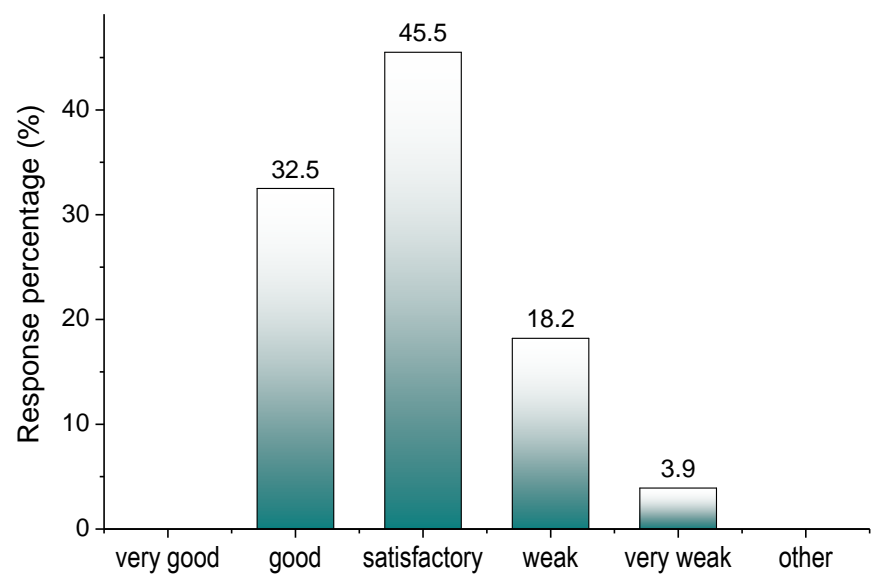

Figure 1. Specialists' opinion regarding the selection quality for sports game in Romania

Most of the answers of the specialists for the second question " How do you appreciate the quality of the selection made in Romania for the handball game?" (Figure 2) were for the "good" option, meaning a total of $36.4 \%$. Another major value of $33.8 \%$ checked the "satisfactory" option, 18.2\% chose the "poor" option, and the "very good" and "very poor" options obtained $6.5 \%$ and $5.2 \%$ respectively from the total answers. The fact that most of the specialists chose the "satisfactory" option denotes the possibility to bring improvements for the selection in the handball game, and the research topic chosen by us is a very important and up-to date.

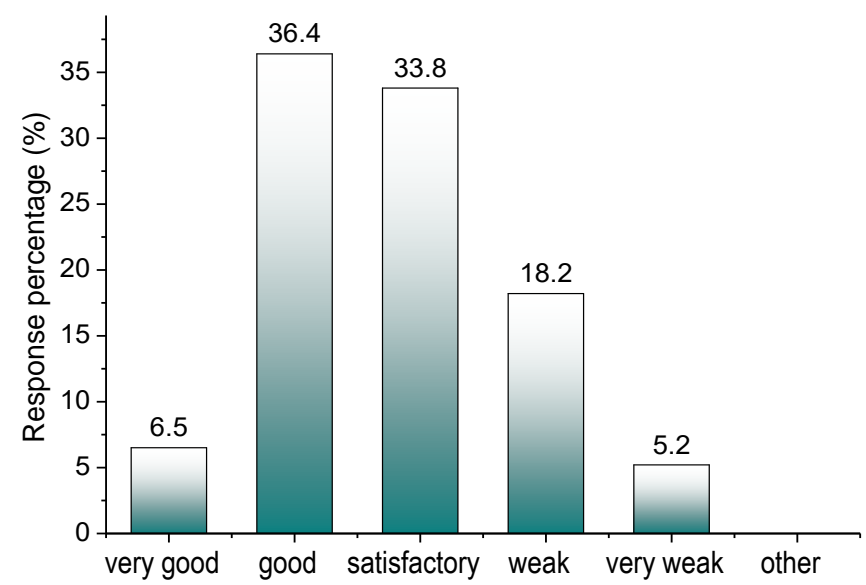

Figure 2. Specialist opinion regarding the handball selection quality from Romania

To the third question "What do you consider to be the most effective selection criteria that specialists should give more importance to?", most of the answers (62\%) focused on the last option answer "all 5 variants", which means: motor, somato-functional, medical, psychological and biochemical criteria. $29.9 \%$ of the respondents checked the "motor" criterion as the most efficient, and $16.9 \%$ chose the "somato-functional" criterion as the most efficient criterion for the selection process. Most specialists considered that all the selection criteria are very important, correctly appreciating the importance of interdependence and the influence of these criteria on obtaining sports performance (Figure 3). 


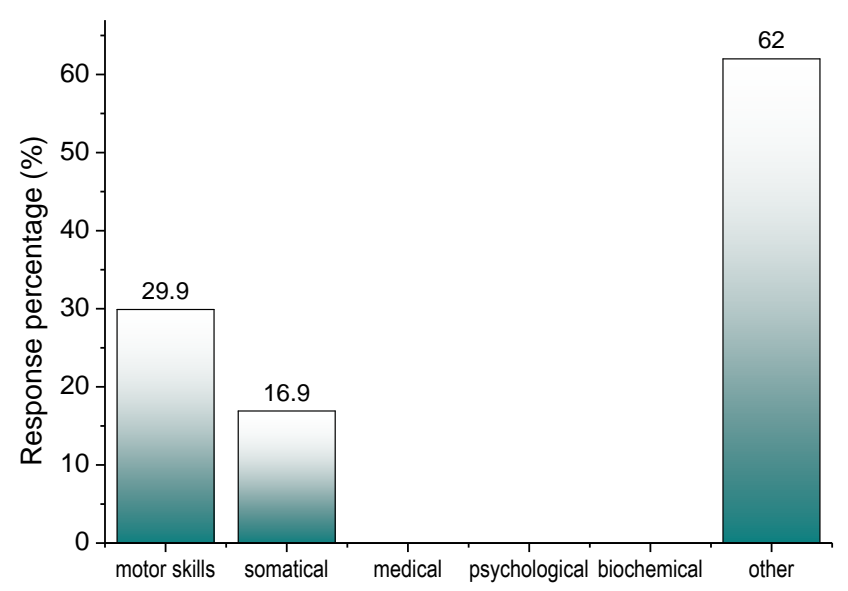

Figure 3. Specialists' opinion regarding the most efficient selection criterions

"Physical training" was the most appreciated option by the specialists surveyed to the question "In your opinion, which of the components from sports training occupies the most important place in sports training?", totaling $54.5 \%$ of the answers. $28.6 \%$ of the answers surveyed the "technical training" option, and 11.7\% chose "tactical training". $2.6 \%$ of respondents considered that the psychological and theoretical training is also very important having a total percentage of $2.6 \%$ each (Figure 4 ).

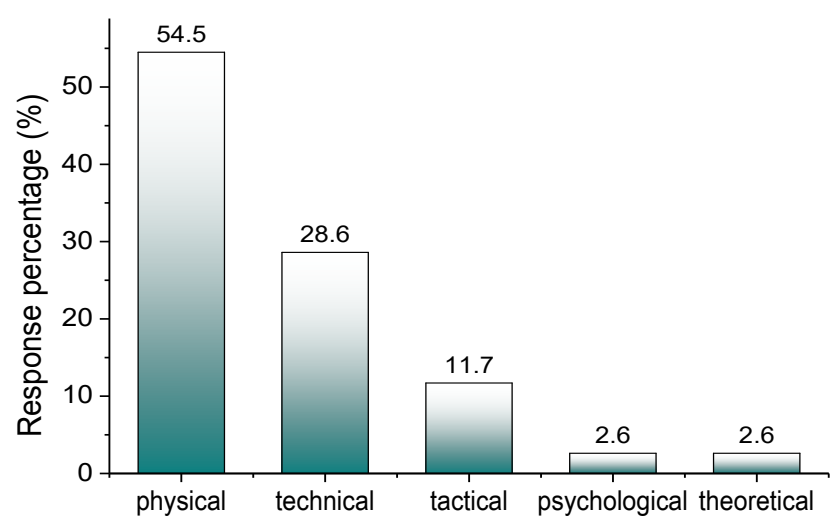

Figure 4. Specialists' opinion regarding the importance of sports components in training

For question number five "Which of the listed motor qualities play an important role in optimizing the selection process of handball athletes? (Indicate three motor qualities)", $49.3 \%$ and $48 \%$ concerned "speeding" and "coordination skills". 38.9\% of the answers were for "speed in speed", $29.9 \%$ ticked one of the three variants as "resistance in speed", $24.7 \%$ of the answers were for "speed", $22 \%$ also have "mobility" as a motor quality necessary for a handball player, and $20.8 \%$ also chose "strength". The lowest percentage was registered by the motor quality "resistance", only $11.7 \%$ chosen by questioned subjects. We could observe that most of the specialists, for the three variants they could choose from the 8 proposed motor qualities, chose a motor quality aimed at skill (coordinative abilities), one aimed at strength, and one aimed at speed. Moreover, the percentage obtained by the variant "coordinative abilities" is very close to the variant "skill in speed regime", two motor qualities that are closely related (Figure 5). 


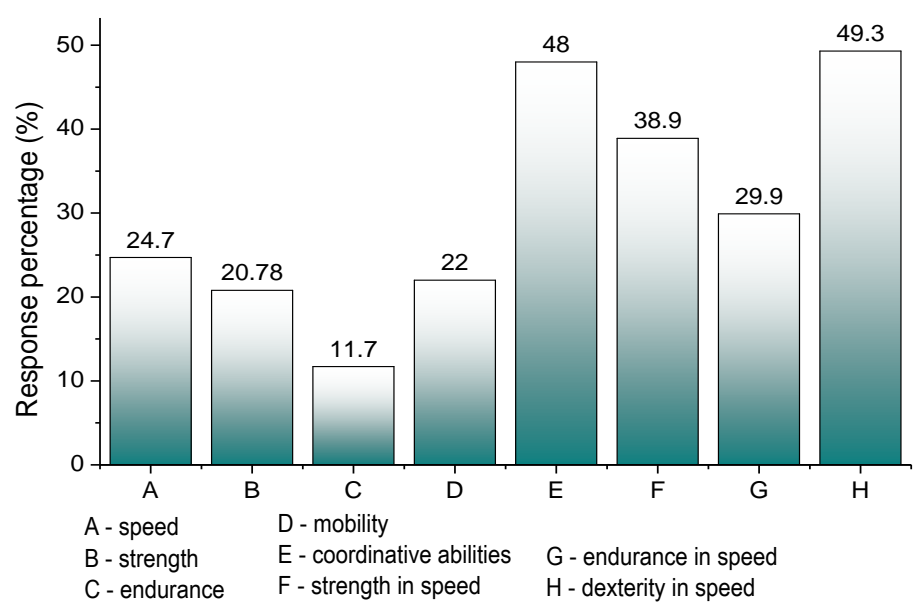
process

Figure 5. Specialists' opinion regarding the importance of motor skills in the handball selection

For question number six, "Which of the components of coordination abilities occupy an important place in the training process of handball players?", the majority of surveyed specialists $(76.6 \%)$ chose "the ability to coordinate their movements", $28,6 \%$ of them chose "spatial orientation capacity", $24.7 \%$ were of the opinion that "appreciation and regulation of space-time parameters" is the most important component of the coordinative capacities with special influence in the process of an- training of athletes, and $11.7 \%$ considered "the sense of rhythm to be important". "Ability to maintain balance" and "ambidexterity" respectively recorded the weakest percentages of $10.4 \%$ and $3.9 \%$ respectively (Figure 6).

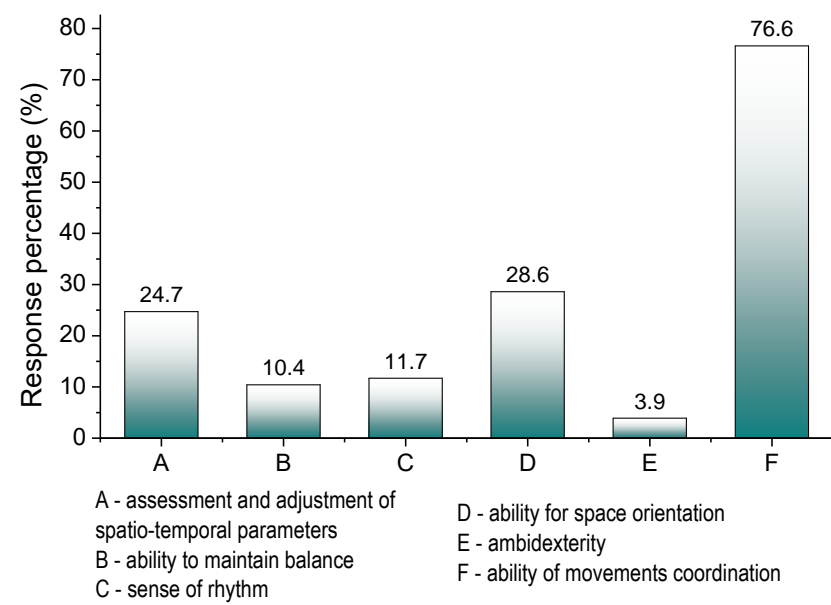

Figure 6. Specialists' opinion regarding the coordination abilities components related with the training process

A majority (58.4\%) of the answers to the seventh question "How do you assess the level of development of coordination abilities in the case of children aged 10-12 years old selected for handball game?" targeted the "medium" option, $23.4 \%$ of the specialists chose the "good" answer, 11.7\% appreciated the level of development of the children's coordination abilities as "weak", and $6.5 \%$ said that it is "very weak". The fact that most of the answers are at the "average" level and below this level and at the same time the fact that no specialist ticked the "very good" answer, shows their dissatisfaction with the degree of development of children's coordination skills at this level (Figure 7). 


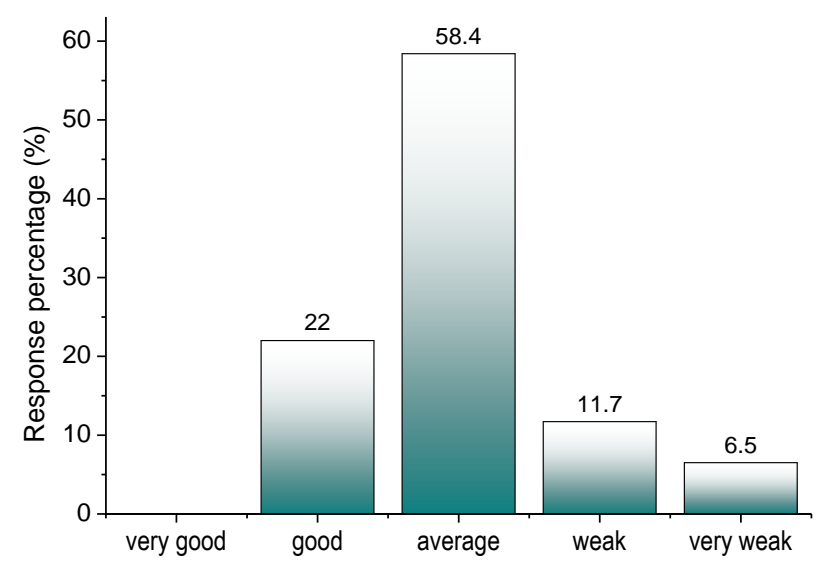

Figure 7. Specialists' opinion regarding the level of coordination abilities development of children aged $10-12$

For the question "How much importance is given to the development of coordination abilities of children aged 10-12 in handball training?", most specialists $(71.4 \%)$ chose the "average" option, 15.6\% and 12,9\% chose the "small" and "large" options, respectively. The answers of the specialists allow us to extract the idea that they try to develop the coordination abilities within the trainings (Figure 8).

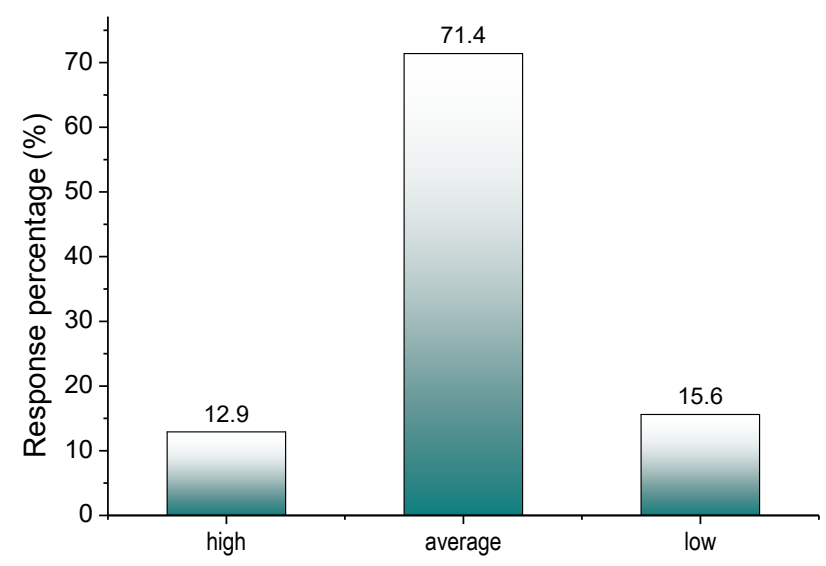

Figure 8. Specialists' opinion regarding the importance of coordinative abilities in the training process

To the question number 9, "What number of lessons per week (or lesson topics), from the annual training planning of your handball players, do you give for the development of coordination abilities?", 31.1\% of the answers were for "three lessons", $24.4 \%$ said that in "two lessons" each week they aim to develop coordination abilities, $16.9 \%$ give only one lesson for this, and $11.7 \%$ of them develop coordination abilities in 4 weekly lessons. 16.9\% of those surveyed chose "other options", in which they said that they proposed means of developing coordination abilities in each training lesson. From the answers given, it can be seen again, the major importance that specialists give for the development of this motor quality (Figure 9). 


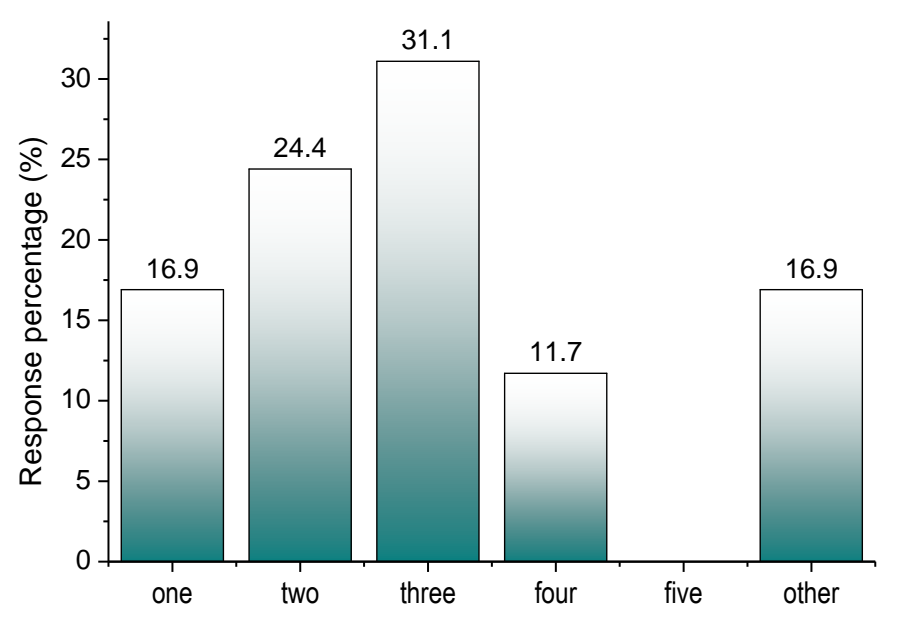

Figure 9. Specialists' opinion regarding the number of lessons from the weekly training process related to coordinative abilities

To the question "In what period of training of handball athletes is more importance given to the development of coordination abilities?", almost half of the answers (49.3\%) referred to the "training period", $23.4 \%$ of specialists answered, "the period pre-competitive", $19.5 \%$ develop this quality during the transition period, and $7.8 \%$ of the surveyed specialists chose the competitive period. We can extract from the recorded answers the fact that most specialists develop this quality before the competitive period, giving it due importance (Figure 10).

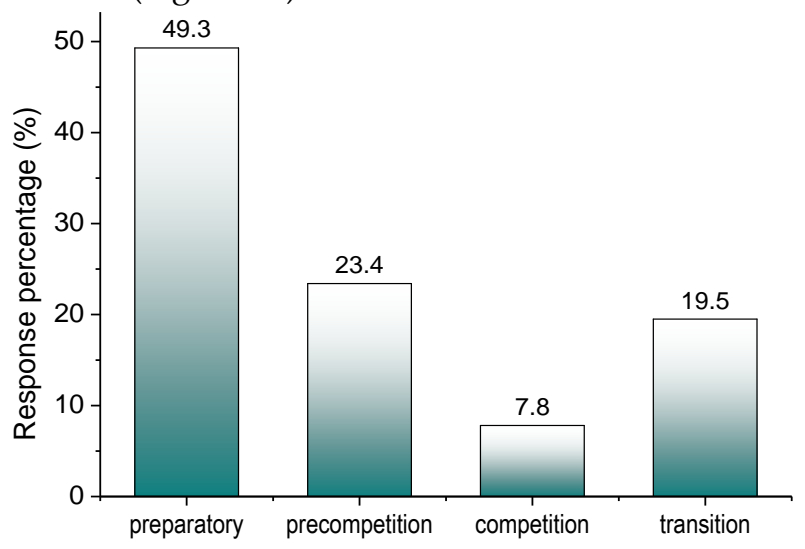

Figure 10. Specialists' opinion regarding the chosen period when they develop coordinative abilities of the children in the handball game

To the question number 11 "In which part of the handball training lesson do you approach the development of coordination abilities?", the specialists answered mostly $(49.3 \%)$ "the preparatory part", very close to most of the answers is the second option "the fundamental part" with $42.8 \%$ of the answers, and in the final part $6.5 \%$ of those surveyed develop coordination abilities. The fact that many teachers and coaches choose to develop this quality in the fundamental part of the training lesson highlights, again, the importance given to this motor quality (Figure 11). 


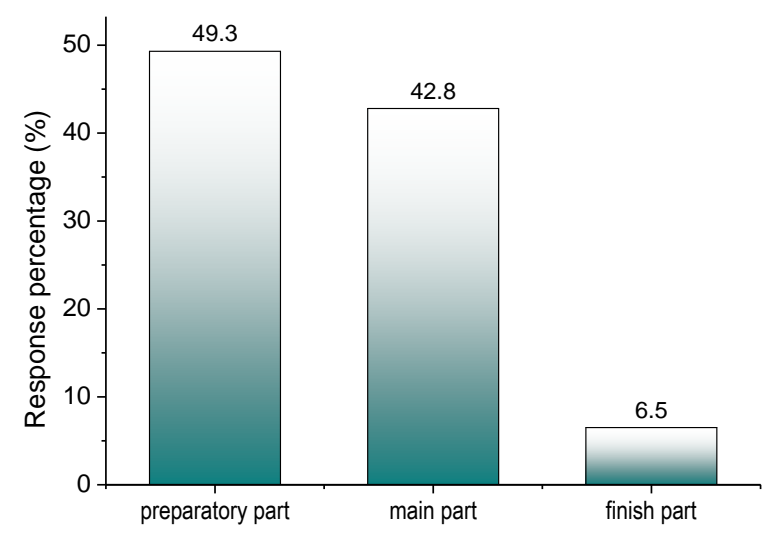

Figure 11. Specialists' opinions regarding which part of one lesson is chosen to develop coordinative abilities

To the second last question of the proposed questionnaire "How much time do you spend to teach using coordinating abilities in a handball sports training lesson?", 74\% of those surveyed estimated the time between 5 and 10 minutes, other specialists $(6,5 \%)$ said that they give between 1 and 5 minutes to the development of coordinated abilities, and $19.5 \%$ gave "other variants", most of them framed these variants between 10-15 minutes or over 15 minutes. Following the analysis of these answers, we can say that the actual time given to the development of coordination abilities is relatively short and can be improved (Figure 12).

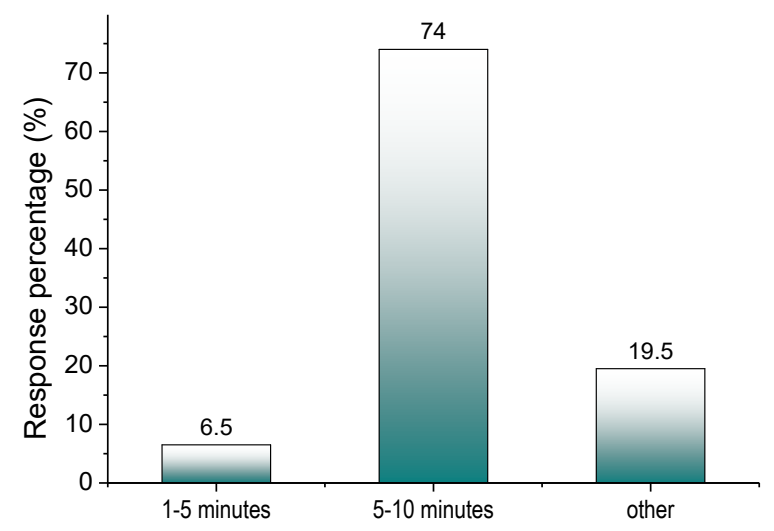

Figure 12. Specialists' opinion regarding the allocated time frame from one training lesson in which they try to develop coordinative abilities

The last question of the questionnaire concerns the importance of the level of development of coordination skills in optimizing the selection process of children for the handball game. The answers to this question focused on the "very important" and "important" variants, the percentages being very close to $51.9 \%$ for "very important", respectively $48.1 \%$ for the second option. From here we can conclude the importance we must give to the development of these motor qualities, but also the major influence it has in optimizing the selection system in our country for the handball game (Figure 13). 


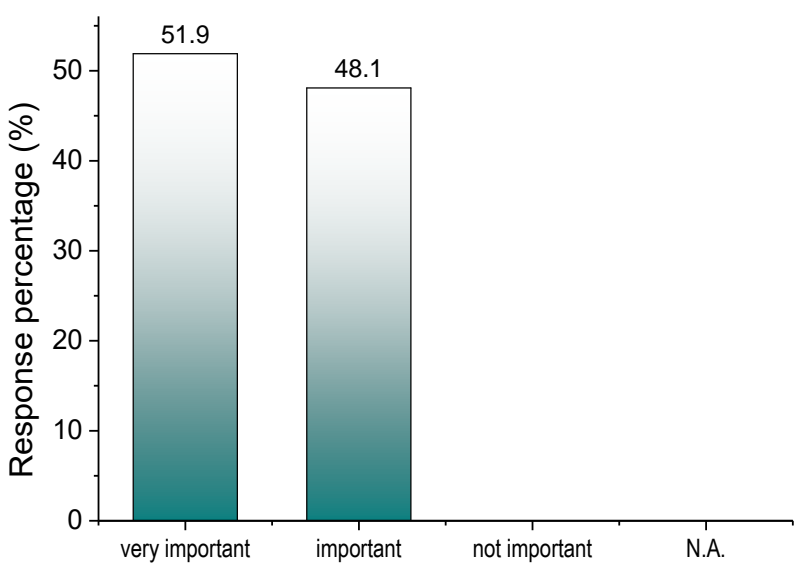

Figure 13. Specialists' opinion regarding the importance of using development of coordinative abilities in the children handball game selection process

\section{Conclusions}

Trying to summarize, in a few sentences, the answers of the specialists to the questions of the questionnaire proposed in this paper, we can say that the selection process in sport games in general, and in handball in particular in our country does not live up to the expectations of specialists. At the same time, they consider that the development level of the coordinative abilities of 10-12 years old children is medium to weak, and the actual workplan in the training process for the development of this quality is quite small. Most specialists do this in 2-3 training lessons each week, 5-10 minutes each, either in the preparatory part or in the fundamental part of the lesson. The respondents also stressed the importance of developing coordination abilities to optimize the selection process of children who play handball, saying that this motor quality is very important in this area.

The answers of the specialists in the field confirmed to us the fact that the (theoretical) in-depth study of the sports selection process in Romania is required, bringing practical solutions and contributions in this regard, and giving the necessary importance to the development of coordination abilities can contribute to optimizing this process.

Author Contributions: Conceptualization, I.P.; methodology, I.P.; validation, I.P.; formal analysis, I.P.; investigation, I.P.; resources, I.P.; data curation, I.P.; writing-original draft preparation, I.P.; writing-review and editing, I.P.; visualization, I.P.; supervision, I.P.; project administration, I.P.; funding acquisition, I.P.

Funding: Not applicable.

Data Availability Statement: Not applicable.

Acknowledgments: Not applicable.

Conflicts of Interest: The authors declare no conflict of interest.

\section{References}

1. Sands, W. A., et al. Modern techniques and technologies applied to training and performance monitoring. International journal of sports physiology and performance 2017, 12.s2, 63-72.

2. Rajšp, A.; Fister, I. A systematic literature review of intelligent data analysis methods for smart sport training. Applied Sciences 2020, 10.9, 3013.

3. Guerriero, A.; Varalda, C.; Piacentini, M.F. The role of velocity based training in the strength periodization for modern athletes. Journal of Functional Morphology and Kinesiology 2018, 3.4, 55.

4. Nabatnikova, M.I. On the content of training young athletes. Scientific and sports bulletin 1982, 1, 6-9.

5. Manno, R. Les bases de l’entrainement sportif, EPS: France, 1992.

6. Baştiurea, E. Handbal: concepte, principii şi căi de perfecţionare ale antrenamentului, Academica: Romania, 2007.

7. Shuba, L.; Chukhlantseva, N.; Shuba, V. Complex development of physical characteristics of 11-12-year-old boys using basketball elements for physical education. Journal of physical education and sport 2018, 18.2, 739-744.

8. The XXXII FIMS World Congress of Sports Medicine. Available online: http://www.fimsroma2012.org (accessed on 03.06.2021). 
9. Juravle, I. Contribution regarding handball selection using graphical analysis method. Annals of "Dunarea de Jos" University of Galati, Fascicle XV 2012, 82-87.

10. Camacho-Cardenosa, A., et al. Anthropometric and physical performance of youth handball players: The role of the relative age. Sports 2018, 6.2, 47.

11. Tróznai, Z, et al. Talent Selection Based on Sport-Specific Tasks Is Affected by the Relative Age Effects among Adolescent Handball Players. International Journal of Environmental Research and Public Health 2021, 18.21, 11418.

12. Simion, G.; Stănculescu, G.; Mihăilă, I. Antrenament sportiv, concept systemic, Editura Ovidius University Press: Constanța, 2011.

13. Till, K.; Baker, J. Challenges and [possible] solutions to optimizing talent identification and development in sport. Frontiers in psychology 2020, 11, 664 .

14. Altavilla, G. Monitoring training to adequate the teaching method in training: An interpretative concepts. Journal of Physical Education and Sport 2019, 19, 1763-1766.

15. Nuriddin, N. The main concepts and current problems of the preparing system of runners in modern sport theory. Central Asian journal of theoretical $\mathcal{E}$ applied sciences 2021, 2.5, 1-8.

16. Kaufman, K.A.; Glass, C.R.; Pineau, T.R. Mindful sport performance enhancement: Mental training for athletes and coaches, American Psychological Association; 1st edition, 2018.

17. Maksymchuk, B., et al. Training Future Teachers to Organize School Sport. Revista Romaneasca Pentru Educatie Multidimensionala 2020, 12.4, 310-327.

18. Marczinka, Z. What's the difference? Coaching female and male handball players. EHF Scientific Conference, $2011,89-93$.

19. Moisescu, P. Determining the optimal period in developing the coordinative capacities in male elementary school pupils. The Annals of the University Dunărea de Jos of Galați, Fascicle XV, Physical Education and Sport Management 2010, 49-52.

20. Increasing the efficiency of training, Communications, Technical-Methodical Commission. Available online https://frh.ro (accessed on 21.10.2021).

21. Leuciuc, F. Longitudinal study on the effectiveness of the game actions in men's handball top competitions (1998-2016). Kinesiologia Slovenica 2018, 24:2, 36-43.

22. Massuça, L.M. Expertise evaluation of technical and tactical proficiency in handball: differences between playing status, EHF Scientific Conference, 2011, 282-286.

23. Prisăcaru, I. R.; Marinescu, G. Analysis of tactics and offensive playing systems in elite European teams, in vue of optimizing attack for Romanian top handball male teams. Discobolul - Revista UNEFS de cultură, educaţie, sport şi kinetoterapie, 2010, 4:22, 3040.

24. Ghervan, P. Selecția și primii pași în handbal, Editura Didactică și Pedagogică: București, 2014.

25. Leuciuc, F.V. Somatic Model and Performance Age in Elite Handball (Study Case: Male Champions League Final Four 2012). Gymnasium, Scientific Journal of Education, Sports and Health 2012, 1:13.

26. Vila, H.; Manchado, C.; Rodriguez, N.; Abraldes, J.A.; Alcaraz, P.E.; Ferragut, C. Anthropometric profile, vertical jump, and throwing velocity in elite female handball players by playing positions. Journal of Strength Condition Resistance 2012, 26:8, 21462155.

27. Monea, D.; Ormenisan, S.; Grosu, E.; Apostu, P.; Nica, C.; Badea, D. Optimizarea procesului de selecție în jocul de fotbal la copii în vârstă de 10-12 ani. Revista Studia Universitatis Babeș- Bolyai 2015, 60:2, 67-74.

28. Karabatic, L. L'entretien du Lundi, "je suis un Hansballeur". Available online: www.ff-handball.org (accessed on 12.09.2021).

29. Swiss Olympic, Manuel de diagnostic de performance, 2015. Available online: https://www.swissolympic.ch (accessed on 02.11.2021)

30. Lidor, R.; Falk, B.; Arnon, M.; Cohen, Y.; Segal, G.; Lander, Y. Measurement of talent in team handball: the questionable use of motor and physical tests. The Journal of Strength and Conditioning Research 2005, 19:2, 318-325.

31. Zubik, M.; Spieszny, M.; Sumara, M. Identifying talented handball players - The possibilities of examining the players by means of speed-force and coordination tests. Central European Journal of Sport Sciences and Medicine 2013, 4:4, 53-62.

32. Specific principles and means of training for Minihandball and juniors - IV, Communications, Technical-Methodical Commission. Available Online: http://www.frh.ro (accessed on 15.08.2021).

33. Handball Selection. Available Online: http://www.esbm-handball.org (accessed on 15.08.2021).

34. Marsh, J.L. A study of predictability of ability in handbal, Physical Education Thesis, 1972.

35. Leveque, M. Psychologie du metier d'entraineur; l'art d'entrainer les sportif. Vuibert: France, 2005. 